\title{
Educação popular e pedagogia social: um encontro possível no caso de Porto Alegre?
}

\author{
Fernanda dos Santos Paulo \\ Universidade Federal do Rio Grande do Sul, Porto Alegre, RS-Brasil. \\ fernandaeja@yahoo.com.br \\ Isaura Isabel Conte \\ Universidade Federal do Rio Grande do Sul, Porto Alegre, RS - Brasil.
}

isauraconte@yahoo.com.br

Patricia Rutz Bierhals

Universidade Federal do Rio Grande do Sul, Porto Alegre, RS - Brasil.

patriciabierhals@yahoo.com.br

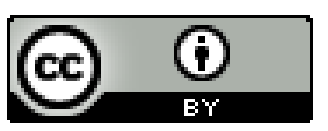

Educação: teoria e prática, Rio Claro, SP, Brasil - eISSN: 1981-8106

Está licenciada sob Licença Creative Common

\section{Resumo}

Este artigo se propõe a apresentar algumas reflexões acerca da educação popular e da pedagogia social, e no bojo destas, problematiza-se o caso de Porto Alegre, apresentando o engajamento de educadores populares, organizados na Associação de Educadores Populares de Porto Alegre - AEPPA, com vistas à luta por formação. O método utilizado se baseia em estudos teóricos e inserção direta em contextos de educação popular, com sínteses e discussões grupais. Como resultado, enfatiza-se que há convergências, mas também desencontros, entre ambas as terminologias e, somam-se a elas, ainda outras, parecidas. A educação popular surge muito fortemente vinculada a movimentos sociais populares e carrega consigo o compromisso pela transformação social. A pedagogia social, por sua vez, nasce no contexto pós-segunda guerra mundial, numa situação de vulnerabilidade, propondo-se a assistência e amenização de sofrimentos. Sob esse aspecto há diálogos possíveis, entretanto, a educação popular possui um caráter marcadamente de classes, com opção pelos (empobrecidos, que, de acordo com Freire, aprendem também a ler o mundo. 0 desencontro ocorre, quando se confundem os termos - educação popular e pedagogia social - como se fossem a mesma coisa, ou se um pudesse substituir o outro. Por fim, como conclusão, pontua-se que a educação popular não exclui a pedagogia social e vice versa, sendo que as duas possuem sentido nos fazeres pedagógicos.

Palavras-chave: Educação popular. Educação social. Movimento Popular. Pedagogia social. 


\title{
Popular education and social pedagogy: is there a possible case in Porto Alegre?
}

\begin{abstract}
This article aims to present some reflections on popular education and social pedagogy, and in the midst of these, be problematized the case of Porto Alegre, presenting the engagement of educators (as) popular, organized (as) in the Association of Popular Educators from Porto Alegre - AEPPA, in order to fight for education.. The method is based on theoretical studies and direct insertion in the context of popular education, with summaries and group discussions. As a result, it is emphasized that there are similarities, but also disagreements between the two terminologies, and adds to them, still others, such. Popular education emerges very strongly linked to popular social movements and carries the commitment to social transformation. The social pedagogy, in turn, is born in the post - World War II in a vulnerable position, proposing assistance and alleviation of suffering. In this aspect there is dialogue possible, however, popular education has a markedly class, with the option (s) impoverished (as), which according to Freire, they learn to read the world. The mismatch occurs when the terms are confused - popular education and social pedagogy - as if they were the same, or if one could replace the other. Finally, in conclusion, points out that education does not exclude the popular social pedagogy and vice versa, and the two have meaning in the educational doings.
\end{abstract}

Keywords: Popular Education. Social Education. Popular Movement. Social Pedagogy.

\section{Introdução}

Por meio deste artigo, buscamos apresentar possíveis encontros, mas, também, desencontros entre a educação popular e a pedagogia social, analisando, de forma específica, o caso da cidade de Porto Alegre (RS). Enfatizamos a temática dos Movimentos Populares, trazendo a interlocução de um coletivo de educadoras populares, cuja denominação é AEPPA ${ }^{1}$. Para esse diálogo, buscamos, prioritariamente, autores que

\footnotetext{
${ }^{1}$ O Movimento Popular de Educadoras nasce em 1996, com um grupo de educadoras vinculadas às creches comunitárias e lideranças de associações de bairro, tendo por objetivo lutar por formação pedagógica na linha da educação popular. Em 2000, desse movimento, cria-se a Associação de Educadores Populares de Porto Alegre (AEPPA) com possibilidade de conveniar com instituições de formação profissional, visando implementar cursos diferenciados para educadores populares. As educadoras e educadores que congregam a AEPPA são trabalhadores no contexto educativo não escolar, sendo alguns associados e outros não.

Atualmente, participam regularmente de reuniões, em torno de 80 educadores. A AEPPA não tem sede própria e realiza os seus encontros na cidade de Porto Alegre, contando com parcerias de associações comunitárias, Mercado Público, entre outros. Uma das autoras do texto é militante desse movimento desde 2002, e vem contribuindo com os processos de formação de educadores populares, a partir de 2003. Na coordenação do Núcleo de Formação, está desde 2010.
} 
discutem a problemática em questão, e, dentre os vários, citamos: Paulo Freire (1981; 2000; 2001 e 2002), Carlos Rodrigues Brandão (2002; 2006), Fred Karl e Johannes Doll (2006), Bernard Fichtner(2009), Maria da G. Gohn (1985;2003), Marlene Ribeiro (2006; 2008), Conceição Paludo (2001), Roberto da Silva(2011) e Raúl Zibechi (2005).

Partindo das discussões de Fichtner (2009), a pedagogia social tem sua origem na Alemanha e surge no contexto pós- segunda guerra mundial. O seu objetivo era trabalhar com crianças e jovens órfãos em situação de vulnerabilidade social. A educação popular, no Brasil e na América Latina, segundo Paludo (2001), surge em um contexto de profunda e dolorosa exclusão social, mas, que por meio de processos de organização popular, busca a transformação da sociedade. Partindo dessas ideias generalizadas, que, ao longo do texto, detalhamos enquanto conceituação, cabe-nos problematizar se é interessante discutir, no contexto brasileiro, a educação popular na relação com a pedagogia social.

Desde já, afirmamos que sim, inclusive, devido a algumas confusões teóricas e, também, a programas executados nas gestões do campo democrático popular, cuja atuação da secretaria de educação e assistência social busca conveniar com associações e movimentos de bairros da cidade de Porto Alegre. A cidade de Porto Alegre está sendo tomada como cidade educadora e, no bojo dessa caracterização, termos como educação social, pedagogia social e educação popular, são contextualizados juntos, parecendo que tudo é a mesma coisa, e que há somente semelhanças e não divergências. Neste artigo, nos propomos a essas discussões, partindo de outros estudiosos, mas, também, da experiência, devido à atuação em processos de educação popular e de seus vínculos com a AEPPA.

\section{Educação popular, movimentos sociais e interlocuções}

No Brasil, de acordo com Brandão (2002), a educação popular está vinculada às experiências educativas desde a década de 1920, fortemente vinculada ao movimento anarquista. Em complemento, Paludo (2001) argumenta que as raízes da educação popular estão colocadas, no país, desde as revoltas dos escravos em favor de sua libertação. Contudo, consistiu, também, no dizer de Brandão, na luta pelo direito à escolarização pública ao longo dos tempos, devido à pressão popular e às condições em que o povo se encontrava, com grande contingente populacional sem acesso às escolas. 
No contexto geral da educação brasileira, Paiva (1973) destaca que, entre as décadas de 1930 e 1940, houve disseminação massiva de escolas pelo país afora, inclusive com cerca de $90 \%$ delas construídas no meio rural. Segundo a autora, foi somente a partir desse período que se popularizou a educação no Brasil, ainda que, no campo, apenas os primeiros anos do ensino primário (anos iniciais) eram oferecidos e, com raríssimas exceções, o ensino fundamental completo. Tratava-se das escolas isoladas, ou escolas de primeiras letras, que, de acordo com Paludo (2001), franqueou ao povo o acesso mínimo aos conhecimentos - ler, escrever e contar, de modo rudimentar - pois, o desenvolvimentismo exigia alguma educação em preparação ao pacote urbano-industrial que estava sendo implementado.

A partir da década de 1950, mais precisamente, a educação popular pode ser descrita como um paradigma político-pedagógico, novo até então, partindo de experiências que se davam em círculos de cultura formados por jovens e adultos (BRANDÃO, 2006). Em sintonia com o processo de educação/alfabetização, o objetivo principal da educação popular era construir com os oprimidos uma educação política, com vistas à mudança da realidade opressora, tendo por intenção a libertação (FREIRE, 2001).

Analisando o contexto da época, percebe-se que, com maior ênfase, a partir da década de 1950, a educação popular no Brasil começa a ser potencializada e adquire força de expressão, sobretudo pela ampliação do acesso às escolas. A figura da escola passou a fazer parte do imaginário social de milhares de pessoas que, talvez, até então, pensavam nunca ter acesso, pois o analfabetismo era bastante naturalizado, inclusive no campo. Desse modo, as informações dos rádios se popularizavam e fazia-se educação radiofônica, por meio do Movimento de Educação de Base (MEB), de acordo com Wanderley (1984), algo que ajudava a disseminar a concepção de educação. Onde não havia escolas, principalmente, os adultos eram alfabetizados em círculos de cultura, via associações de bairros e comunidades.

Assim, independente dos formatos em que se conseguia alfabetizar, fazendo, juntamente, aquilo que Freire (2001) chama de leitura de mundo - um dos propósitos da educação popular - fomentava-se a organização popular, que, por sua vez, foi promovendo o surgimento dos Movimentos Populares ou fortalecendo os já existentes.

A educação popular, não podendo ser entendida como algo perfeito, tampouco isenta de críticas, como bem coloca Brandão (2002), se faz presente em muitos contextos, tanto na esfera dos Movimentos Sociais Populares como nas políticas públicas. Por meio dela, foi e é 
possível a mobilização social, não só no Brasil, como na América Latina e países empobrecidos da África, de forma especial. Nesse sentido, contribuiu para denunciar regimes opressores, a corrupção de governos, a falta de transparência em esferas públicas, a falta de acesso a serviços básicos, assim como também pautou o problema da terceirização e seus malefícios.

Durante o período ditatorial, no Brasil, continuou havendo maior acesso à escolarização, visto que combater e erradicar o analfabetismo era uma das bandeiras de sustentação do regime. A reestruturação do ensino, portanto, bem como da organização do Estado como num todo, se baseava nos princípios da Segurança Nacional, com vistas à manutenção do Estado autoritário. Assim, nessa organização, prioriza-se o desenvolvimento econômico e, para isto, a educação se vincula ao projeto de modernidade, sendo a educação popular excluída (PALUDO, 2001). De acordo com Wanderley (1984), boa parte da educação popular foi cooptada pela ditadura militar, exemplificando-se, em lugar do MEB, surge o MOBRAL - Movimento Brasileiro de Alfabetização.

De acordo com a mesma autora, a década de 1980, período caracterizado pela retomada da consciência dos direitos na ampla luta pela redemocratização, através dos movimentos políticos e sociais, se dá, também, um grande movimento da educação pública que culminou na Constituição de 1988. Brandão (2002, p.143), também destaca que, naquele momento, surgiram algumas propostas de educação popular na educação pública, e, um exemplo, foi a atuação de Paulo Freire como secretário municipal de educação, na cidade de São Paulo.

Contudo, na década de 1990, a educação popular recebeu inúmeras críticas, como se fosse uma concepção já superada, sobretudo porque aquele contexto estava marcado pelas políticas neoliberais também na educação. Gohn (2003) afirma que os Movimentos Sociais Populares urbanos passaram por uma crise nos primeiros cinco anos da década em questão, resultando numa redução do poder de pressão que haviam conquistado nos anos 1980 . Por outro lado, os Movimentos Sociais Populares do Campo ganhavam força, a exemplo do Movimento dos Trabalhadores Rurais Sem Terra (MST).

Nas cidades vivia-se a crise expressa no desmonte de políticas sociais, na fragmentação das lutas, no aumento do desemprego e da violência urbana, pela flexibilização do mercado 
de trabalho, induzindo ao crescimento do setor informal e terceirização do trabalho (GOHN, 1985, 2003; PERONI, 2003).

Gohn (2003) explicita que, no processo de mudança da conjuntura política, conduzido a partir de 1990, há uma nova configuração dos Movimentos Sociais, nos quais alguns passam a se voltar para ações coletivas, visando resultados ao passo que diminuíram, consideravelmente, os protestos e contestações.

Cabe, ainda, registrarmos que na história do Brasil encontramos diferentes Movimentos Populares com características distintas, mas que tem como dimensão a luta por melhores condições de vida, a exemplo dos movimentos de bairro, de camponeses e operários como diz Mutzenberg (1999). Na definição de Ribeiro (2008, p. 41), "o movimento social popular é educador, enquanto capaz de forjar uma identidade de classe". Zibechi (2005) chega a apontar em seu texto que alguns movimentos assumem a educação e a formação inspirados na educação popular, na revalorização da cultura e da identidade.

Conforme Ammann (1991), a história dos Movimentos Sociais só recentemente ganhou atenção dos cientistas sociais como elemento importante a ser analisado, até porque, como coloca a mesma autora, e Gohn (1985), nem todo Movimento Social é a favor da transformação social, pois a classe dominante também se organiza em movimentos.

A política neoliberal serve como base da terceirização das políticas públicas e da precarização do trabalho. E, nesse sentido, muitos Movimentos Sociais Urbanos, em virtude do contexto político, fragilizaram-se e não conseguiram realizar uma leitura crítica da sua relação com a política da terceirização, o que evidencia uma visível contradição.

É diante desse contexto, no Brasil, ainda na década de 1990, que muitos governos optam pelo repasse das suas responsabilidades, sobretudo nas áreas da educação, assistência e saúde, para entidades do chamado terceiro setor, e, desse modo, renunciam o seu papel como executor direto. Em nosso entendimento, a terceirização de alguns setores de serviços essenciais por parte do Estado é uma das saídas encontradas frente à crise, de um lado, e a acumulação, de outro. Sobretudo, ela surge como alternativa para inclusão social, mascarando a realidade que se expressa na contradição Estado mínimo/Estado máximo frente às políticas públicas, de acordo com Peroni (2003). 
Assim, nos anos de 1990, no auge da força das políticas neoliberais, surgem as políticas sociais que utilizam o termo educação social, tendo referenciais nas leis como o Estatuto da Criança e do Adolescente - ECA, de 1990, e a Lei de Assistência Social - LOAS, de 1993, como salienta Ribeiro (2006). A autora faz um estudo da relação entre educação social e popular, entendendo que a educação social está relacionada à exclusão social de crianças e jovens em condições mínimas de sobrevivência, ou seja, é a educação social como uma política de inclusão.

Conforme entende Romans (2003, p. 54), há "definições da educação social muito distintas, talvez porque se trata de um "termo" de difícil conceitualização. (...) em parte, é consequência de sua própria história e porque a educação tende a variar conforme a ideologia e as políticas sociais dela derivadas".

Também, percebemos que o conceito de educação social, muitas vezes, está relacionado a práticas da educação não formal, e é, ainda, designado como pedagogia social. No caso da utilização do termo pedagogia ao invés de educação, chamamos a atenção para o fato de que a educação é bem mais abrangente do que pedagogia, embora a última esteja relacionada a processos educativos. Na maioria dos casos, a chamada educação social é utilizada para designar algum tipo de trabalho socioeducativo de prevenção, controle e mudanças.

Romans (2003), em um texto intitulado A educação social no Brasil: alguns desafios e armadilhas, define a educação social enquanto, fundamentalmente, ação, práxis, intervenção sistemática, alicerçando suas premissas em Paulo Freire. Ribeiro (2006, p. 171) aponta que há uma despolitização desse conceito, o que revela a força das políticas neoliberais que precisam se utilizar do discurso da exclusão/inclusão para ocultar a “malvadez com que o capitalismo aparece na história"(FREIRE, 2002, p. 48).

Voltando à definição de Romans (2003), consideramos importante destacar que Freire não falava em educação social e, sim, em educação popular, e também denominava os educadores que trabalhavam em espaços educativos não formais como trabalhadores sociais. 
O que podemos perceber dessas trocas entre as terminologias, intencionais ou não, é que, de um lado aparece a educação social como uma política de inclusão, como pontua Ribeiro (2006) e, de outro, se anula toda história da educação popular no contexto Latinoamericano. Nas palavras da mesma autora, ao ocultar a educação popular, também a negamos como sendo uma iniciativa dos Movimentos Sociais Populares, principalmente após o final dos anos de 1970, sobretudo no contexto brasileiro.

Nas experiências de Porto Alegre, a discussão da educação social está vinculada à Fundação de Assistência Social e Cidadania (FASC), tanto é que no histórico da política de assistência do município, o que hoje conhecemos como FASC, era denominado como Fundação de Educação Social e Comunitária (FESC) ${ }^{2}$.

Desde a década de 1990, a prefeitura municipal de Porto Alegre tem trabalhado em parceria com as instituições comunitárias para executar a política da educação infantil e assistência nas comunidades mais empobrecidas, via convênios. Segundo Susin (2009), a parceria do movimento social comunitário com o poder público possibilitou a expansão da educação infantil. De outro modo, o movimento comunitário, ao não realizar uma leitura e análise crítica do significado das parcerias, em grande medida, não percebeu as consequências que poderiam emergir, tanto positivas, e, especialmente, as negativas. Assim, esses movimentos comunitários, além de permanecerem com suas ações coletivas de reivindicação e contestação por melhores condições de vida, passaram a executar políticas públicas, o que mais tarde veio a fragilizar esses espaços.

Essa parceria entre o poder público e a sociedade civil, na execução tanto da política da educação como da assistência social, em Porto Alegre, se utiliza de conceitos da educação popular e social para justificar a relação entre Estado e Sociedade Civil. Nos últimos anos, os convênios entre Município e Sociedade Civil organizada, tem aumentado em quantidade, o que, de certa forma, é positivo, por possibilitar à população o acesso às políticas públicas; de

\footnotetext{
${ }^{2}$ Disponível em: http://www2.portoalegre.rs.gov.br/fasc/default.php?reg=4\&p secao=55. Acesso: 27/06/2012.
} 
outro, consideramos um grande problema quando as lideranças são transformadas em cabos eleitorais da política partidária.

No contexto explicitado, ocorre que os movimentos comunitários, que buscavam a transformação das condições econômicas e políticas, passam a não mais ter tempo para reunir-se, discutir e lutar por essas pautas, pois as lideranças desses movimentos passam a ter a responsabilidade de fazer a gestão das políticas de convênios e de gerir a política partidária, em vários casos.

Na AEPPA, por exemplo, desde 2002 há um núcleo de formação que se destina a estudar e dialogar sobre as questões que envolvem a vida do educador popular, assim nomeado. Desse modo, muitos deles participam de espaços formativos e vem percebendo que, assim como os dirigentes das instituições comunitárias, são também, por vezes, cooptados pelo Estado.

Ao que pudemos experienciar, essa percepção acontece em muitos casos, quando da existência de uma diferença gritante entre a educação oferecida diretamente pelo Município e aquela executada por meio de convênios com associações comunitárias. Diferenças que são percebidas desde as condições de trabalho, implicando, quando via associações, em rebaixamento do salário, maior carga horária, falta de recursos didático-pedagógicos, espaço adequado para formação etc.

Os educadores populares vinculados a convênios comunitários de políticas de educação municipal, seja via Creche Comunitária, Alfabetização de Adultos, Projeto Cidade Escola e Projeto Mais Educação (Ensino fundamental), recebem baixos salários, não possuem formação profissional para atuação e são contratados como: educador assistente, monitor, auxiliar de desenvolvimento infantil, educador oficineiro e voluntário, em alguns casos.

$\mathrm{Na}$ assistência social, executando de forma indireta políticas por meio de convênios, são 415 entidades ${ }^{3}$, onde o educador é denominado como educador social. Muitos projetos técnicos utilizam referências da educação popular baseada em Freire, e, no mesmo documento, fazem a opção pela educação social, como se as duas concepções fossem

\footnotetext{
${ }^{3}$ Disponível em: http://www2.portoalegre.rs.gov.br/fasc/default.php?reg=1\&p secao=90. Acesso: 27/06/2012.
} 
semelhantes. Pesquisando o projeto do Serviço de Apoio Socioeducativo em Meio Aberto (SASE) de 2010, verificamos que não há nenhuma referência à educação popular. Em contrapartida, há registrado que a "perspectiva socioeducativa dialoga com o que designamos de educação social". No projeto mencionado, apresenta-se o seguinte: "Para a educação social são imprescindíveis o exercício da cidadania e as possibilidades da integração dos indivíduos no espaço social das diferenças, não em padrões ou convenções de comportamento, condutas, atitudes, ações ou pensamentos" (PORTO ALEGRE, 2010, p.5). Abaixo dessa afirmação, o texto recebe a interlocução de Freire, assim explicitada: "Para tanto, o referencial dialógico constituído pelas teses Freireanas" (PORTO ALEGRE, 2010, p.5).

Essa confusão teórica tem influência direta na prática das políticas e da formação dos educadores que trabalham nesses contextos, pois

[...] a prática é a razão de ser da teoria, o que significa que a teoria só se constituiu e se desenvolveu em função da prática que opera, ao mesmo tempo, como seu fundamento, finalidade e critério de verdade. A teoria depende, pois, radicalmente da prática. Os problemas de que ela trata são postos pela prática e ela só faz sentido enquanto é acionada pelo homem como tentativa de resolver os problemas postos pela prática. Cabe a ela esclarecer a prática, tornando-a coerente, consistente, conseqüente e eficaz (SAVIANI, 2007, p. 108).

Ao concordar com Saviani (2007), pontuamos que temos um problema no contexto das políticas que se dizem ora de educação popular, ora de educação social, porque na sua execução os conceitos se confundem ou se igualam, perdendo o seu conteúdo real. Um problema decorrente das confusões teóricas é a naturalização da educação social como sendo educação não formal e popular, podendo aparecer esses conflitos na metodologia das práticas sociopedagógicas e na formação de educadores.

Nesse sentido, de acordo com Vale (2001, p.66), "é necessário que tomemos consciência das condições que são adversas a uma prática de educação popular, para que possamos ultrapassá-los". 
Assim, tornam-se tão necessários os espaços de diálogos problematizadores que tomem a educação popular como processo permanente de refletir a militância (FREIRE, 2001).

Diante disso, consideramos importante retomarmos Ribeiro (2006, p. 157), que nos põe a refletir sobre o conceito de educação social, enfatizando que no termo da expressão, o social, parece configurar-se como uma redundância, pois a "educação é reconhecida, por parte das correntes teórico-epistemológicas, da mais conservadora à de esquerda mais radical, pelo seu caráter social".

\section{A Pedagogia social: algumas considerações.}

Segundo Cabanas (1977), a pedagogia social, que é entendida como educação social, surge no final do século XIX e início do século XX, na Alemanha, sendo uma alternativa aos problemas advindos das guerras mundiais, que deixaram problemas como desemprego, grandes migrações e imigrações, favelas, escombros, destruições, poluição, doenças, órfãos, pessoas mutiladas e com outras deficiências.

Naquele período as dificuldades eram muitas. Além da fome e da falta de moradia, milhares de crianças e jovens ficaram órfãos, fazendo com que surgissem políticas assistenciais com ações de voluntariado. Daí decorre o conceito de educação social, influenciados pelo educador suíço Pestalozzi, que tinha, na sua história de vida, uma luta contra a miséria, chegando a abrigar e a alimentar os órfãos. Assim, a educação social nasceu para atuar a partir dos problemas relatados (CABANAS 1997).

Algumas características da pedagogia social aproximam-na da educação popular, pois ela é concebida como aquela que: a) acontece junto às comunidades; b) é a favor de uma coletividade e não apenas do indivíduo (CABANAS, 1997).

De acordo com o mesmo autor, na Alemanha chegou a haver Universidades Populares, tendo como precursor o pedagogo Herman Nohl (1879-1960). Curiosamente, havia uma certa confusão conceitual entre pedagogia social e educação popular, e Nohl, ao fundar a Universidade Popular, em Jena, iniciou um grande debate sobre temas da pedagogia social, pois para esse educador a pedagogia social era entendida como educação popular, tendo um caráter menos assistencial. 
Cabanas (1997) aponta que, por alguns anos, tanto a pedagogia social como a educação popular, na época da República de Weimar, foram suprimidas por questões políticas-ideológicas conduzidas por Hitler. Tais concepções foram postas de lado e, em lugar delas, trabalhou-se pela resolução de problemas sociais. Ao final da II Guerra, a teoria da pedagogia social aproximou-se novamente ao pensamento de Nohl, com a tentativa de reconstruir suas próprias bases científicas. É, também, diante desse contexto que emerge a Associação Internacional de Educadores de Jovens Inadaptados (AIEJI), atualmente renomeada como Associação Internacional de Educadores Sociais, por meio da qual se tem difundido, mundialmente, a pedagogia social (RIBEIRO, 2006).

Ao contrário de uma visão de pedagogia assistencial, Ribeiro (2006) enfatiza que na então URSS (União das Repúblicas Socialistas Soviéticas), foram significativas as experiências de pedagogia social, a partir de educadores como Pistrak e Makarenko. Naquele país, a pedagogia social trabalhava com as questões de pobreza, miserabilidade e delinquência de jovens, mas ia muito além da perspectiva assistencial primeira; a educação era vinculada com a transformação revolucionária do país, sendo que os jovens eram transformados em sujeitos daquele processo.

A pedagogia social, no Brasil, está de alguma forma relacionada à concepção de educação popular, seja para aceitá-la ou negá-la, bem como vinculada à demanda de busca pela profissionalização de educadores que trabalham em diferentes contextos educativos e que não possuem uma formação específica.

No Brasil, de acordo com Silva (2011), aconteceu, em 2006, o I Congresso Internacional de Pedagogia social - CIPS. Segundo o mesmo autor, desde então, houve um compromisso de solidificar a pedagogia social como a Teoria Geral da Educação Social. Na perspectiva de Silva, ao que percebemos, a teoria de Paulo Freire é considerada como fundamentação teórica da pedagogia social no contexto brasileiro, no qual, não raras vezes, aponta-se o termo educação social em substituição ou assemelhado à educação popular. Freire, um dos 
educadores e teóricos da educação popular, se faz presente em cinco textos, dos sete artigos que discutem as Reflexões sobre a Pedagogia social no Brasil ${ }^{4}$.

Coerente com a história da educação popular no Brasil, Graciani (1999) concebe a educação popular como base para a pedagogia social de rua, e diz entender a educação popular como prática social que propõe a transformação social. Da mesma forma, Scocuglia (2009) defende que a pedagogia social no Brasil, na perspectiva Freiriana, pode vir a se constituir numa educação contra-hegemônica, ou seja, educação popular.

Fred Karl e Johannes Doll (2006, p.46) apontam que "no contexto brasileiro, a pedagogia social não alcançou a mesma atenção como nos países europeus", e talvez esteja aí uma possibilidade de refletir sobre a importância da educação popular no e para o Brasil e, também, destacar que esses autores consideram que se trata não de uma coisa só, mas de duas, o que muito nos interessa nesta reflexão.

Para Silva (2011), a pedagogia social possui vocação para a libertação e emancipação, abrangendo todos os setores da sociedade. O autor cita Freire (1981), destacando que a libertação dos oprimidos não se dá através de um processo unilateral. Portanto, consideramos importante relacionar a educação popular como opção para a construção prático-teórica de uma pedagogia social, levando em conta os processos de experiências educativas plurais.

Talvez, um dos limites da construção de uma pedagogia social no Brasil seja, justamente, o abandono do termo educação popular, substituindo-o por educação social (RIBEIRO, 2006). Sendo, assim, deixamos o questionamento: como a pedagogia social brasileira, no contexto da América Latina, pode representar uma perspectiva crítica e contrahegemônica, sem importar modelos pré-concebidos?

\section{$4 \quad$ Reflexões Finais.}

Nesse breve estudo, ainda preliminar, temos a impressão de que a discussão acerca das diferenças e semelhanças da pedagogia social e da educação popular é muito incipiente

\footnotetext{
${ }^{4}$ SILVA, Roberto da e outros, (Orgs.), 2011. Pedagogia social: contribuições para uma teoria geral da educação social. São Paulo: Expressão e arte (volume II).
} 
e, portanto confusa. Ainda mais, quando se usam terminologias do campo político eleitoral de esquerda como se tudo fosse a mesma coisa e, de fundo, está se negando ou deixando de usar a terminologia educação popular, pelo fato de parecer mesmo fora de moda, anacrônico, ou, na verdade, por incomodar já que remete a um debate com recorte de classes.

Por outro lado, há alguns espaços de militância da educação popular em que é possível discutir, estudar a até mesmo pesquisar, com vínculo em universidades, sobre o tema, o que nos parece positivo. Outrossim, alguns textos e artigos de alguns doutores vinculados às temáticas tem sido muito relevantes para contribuir na desconstrução de certas misturas, nem sempre tão oportunas.

A AEPPA, como caso específico, chega a fazer algum debate em torno desses conceitos, mas ainda há muito que avançar, pois, a imposição dos termos confunde-se na sociedade, e muitos educadores vivem em comunidades consideradas carentes e atuam nas políticas de convênios, com trabalho precarizado e com uma carga horária de 40 a 44 horas semanal, o que minimiza o tempo para estudos.

A educação popular possui uma marca e um lugar bem definido, apesar das distorções feitas por alguns teóricos e mesmo por parte de apropriações indevidas e dos discursos de poderes públicos. A pedagogia social, por sua vez, também tem um lugar e, segundo podemos avaliar, possui um caráter mais de remediar do que de transformar, mas, nem por isto, podemos desconsiderá-la. Ela é importante sim, dentro de um contexto, mas não pode e nem deve ser confundida, tampouco substituir, a educação popular, embora possam dialogar. Uma não se sobrepõe a outra, contudo temos teorias suficientes e consistentes para dizer se tratar de uma ou outra, em que sentido convergem e em que direção não caminham juntas.

Coerentemente com o pensamento de Freire, enfatizamos a educação popular e entendemos que ela está intrínseca na história dos Movimentos Populares, mas que pode estar, também, na escola pública, como defende Ana Maria Vale (2001), Carlos Rodrigues Brandão (2002; 2006) dentre tantos outros. Para entendê-la e praticá-la, são necessários espaços de formação para refletir a coerência entre a prática e a teoria, para não 
incorrermos no erro de pensar que realizamos educação popular, quando, na realidade, estamos fazendo qualquer outra coisa.

Parece-nos que um dos desafios postos é o de promoção de diálogos críticos sobre a educação popular e a educação social, de forma especial, nas comunidades que estão diretamente ligadas a esses termos, para então discutir que pedagogia social se pensa ou até mesmo se ela é necessária.

\section{Referências}

AMMANN, S. B. Movimento popular de bairro: de frente para o estado, em busca do parlamento. São Paulo: Cortez, 1991.

BRANDÃO, C. R. O que é Educação Popular. São Paulo: Brasiliense, 2006.

BRANDÃO, C. R. A educação popular na escola cidadã. Petrópolis: Vozes, 2002.

CABANAS, J. M. Q. Antecedentes históricos de la educación social. In: PETRUS, A. (Org.). Pedagogia social. Espanha: Ariel, 1997. p.68-91.

FICHTNER, B. Pedagogia social e trabalho social na Alemanha. In: MOURA, R., NETO, J. C.. de S. e SILVA, R. (Orgs). Pedagogia social. São Paulo: Expressão \& Arte Editora, 2009. p. 43 -50.

FREIRE, P. Pedagogia da Autonomia: saberes necessários à prática educativa. São Paulo: Paz e Terra, 2002.

FREIRE, P. Política e educação: ensaios. São Paulo: Cortez, 2001.

FREIRE, P. Pedagogia da indignação: cartas pedagógicas e outros escritos. São Paulo: UNESP, 2000.

FREIRE, P. Pedagogia do oprimido. 11ed. Rio de Janeiro: Paz e Terra, 1981.

GOHN, M. da G. Os movimentos sociais no Brasil: novos atores sociais. IHU On-Line, São Leopoldo, 11 de agosto de 2003 ( entrevista impressa). 
GOHN, M. da G. A força da periferia: a luta das mulheres por creches em São Paulo. Vozes, 1985 .

GRACIANI, M. S. S. Pedagogia social de rua: análise e sistematização de uma experiência vivida. São Paulo: Cortez e Instituto Paulo Freire, 1999.

KARL, F.; DOLL, J. Demência e pedagogia social. Estudos interdisciplinares sobre o envelhecimento. Porto Alegre, v. 10, n.2 , p. 45-56, s/m (sem mês). 2006.

MUTZENBERG, R. Construção de sentido pelos movimentos sociais. In: FONTES, B. A. S. (Org.). Movimentos sociais: motivação, representação e produção de sentido. Recife: UFPE, 1999. p.123-156.

PAIVA, V. Educação popular e educação de adultos - contribuições à história da educação brasileira. São Paulo: Loyola, 1973.

PALUDO, C. Educação popular em busca de alternativas: uma leitura desde o campo democrático popular. Porto Alegre: Tomo Editorial, 2001.

PERONI, V. M. V. Política educacional e papel do Estado: no Brasil dos Anos 1990. São Paulo: Xamã Editora, 2003.

PORTO ALEGRE. Município. Fundação de Assistência Social e Cidadania - Serviço de Apoio Sócio Educativo em Meio Aberto - SASE. Abril, 2010. (Projeto técnico).

PORTO ALEGRE. Município. Disponível em: http://www2.portoalegre.rs.gov.br/fasc/default.php?reg=1\&p secao=90. Acesso em: 27 jun. 2012.

PORTO ALEGRE. Município. Disponível em: http://www2.portoalegre.rs.gov.br/fasc/default.php?reg=4\&p secao=55. Acesso em: 27 jun. 2012.

RIBEIRO, M. Educação popular: um projeto coletivo dos movimentos sociais populares. Perspectiva, Florianópolis, v. 26, n. 1, 41-67, jan./jun. 2008 
RIBEIRO, M. Exclusão e educação social: conceitos em superfície e fundo. Educação e Sociedade, Campinas, v. 27, n. 94, p. 155-178, jan./abr. 2006.

ROMANS, M. Profissão: educador social. Porto Alegre: Artmed, 2003.

SAVIANI, D. Pedagogia: o espaço da educação na universidade. Cadernos de Pesquisa, Campinas, v.37, n.130, p.99-134, jan./abr..2007. Disponível em:< http://www.scielo.br/pdf/cp/v37n130/06.pdf>. Acesso em: 24/07/2013.

SCOCUGLIA, A. C. A pedagogia social de Paulo Freire como contraponto da Pedagogia Globalizada. In: MOURA, R.; NETO, J. C. de S. e SILVA, R. (Orgs.). Pedagogia social. São Paulo: Expressão \& Arte Editora, 2009. p. 225 - 240.

SILVA, R. Visões e concepções necessárias a uma teoria geral da educação social. In: SILVA, R. Pedagogia social: Contribuições para uma teoria geral da educação social. Vol. 2. São Paulo: Expressão \& Arte, 2011.

SUSIN, M. O. K. A qualidade na educação infantil comunitária em Porto Alegre: estudo de caso em quatro creches conveniadas. 2009. 306f. Tese (Doutorado em Educação.) Universidade Federal do Rio Grande do Sul/Faculdade de Educação, Porto Alegre, 2009.

VALE A. M. Educação popular na Escola Pública. 4. ed. São Paulo: Cortez, 2001.

WANDERLEY, E. L. Educar para transformar: Educação popular, Igreja Católica e a política no Movimento de Educação de Base. Petrópolis: Vozes, 1984.

ZIBECHI, R. Os movimentos sociais latino-americanos: tendências e desafios. In: ALGRANATI, C. (Org.). Lutas sociais e "neoliberalismo de guerra" na América Latina. São Paulo: Cortez, 2005. p. 198-225. 